\title{
A SUMMARY OF STRONG GROUND MOTIONS OBSERVED IN THE CANTERBURY EARTHQUAKE SEQUENCE
}

\author{
Brendon BRADLEY ${ }^{1}$
}

\begin{abstract}
This paper provides a summary of the ground motions observed in the recent Canterbury, New Zealand earthquake sequence. The sequence occurred in a region of relatively moderate seismicity, $130 \mathrm{~km}$ to the east of the Alpine Fault, the major plate-boundary in the region. From an engineering perspective, the sequence has been primarily comprised of the initial 04/09/2010 Darfield earthquake (Mw7.1) followed by the 22/02/2011 Christchurch earthquake (Mw6.3), and two aftershocks on 13/06/ 2011 (Mw5.3 and 6.0, respectively). The dense spacing of strong motions in the region, and their close proximity to the respective causative faults, has resulted in strong ground motions far exceeding the previous catalogue of strong motion observed in New Zealand. The observed ground motions have exhibited clear evidence of: (i) near-source directivity; (ii) sedimentary basin focusing, amplification and basin effect refraction; (iii) non-linear site response; (iv) cyclic mobility postliquefaction; and (v) extreme vertical ground motions exceeding $2 \mathrm{~g}$, among others.
\end{abstract}

Keywords: Canterbury earthquake sequence, Severe ground motions, forward directivity, liquefaction.

\section{INTRODUCTION}

The Canterbury earthquake sequence was initiated following the 04/09/2010 Darfield earthquake. As at the end of 2011, this sequence has been particularly active, producing over 100 events of $M_{w}>4$. Figure 1 illustrates the spatial distribution and cumulative event magnitude distribution of this sequence. The sequence has been dominated by four specific events in particular, which are annotated in Figure 1: (i) the 04/09/2010 $M_{w} 7.1$ Darfield earthquake, which initiated the sequence; (ii) the $22 / 02 / 2011 M_{w} 6.2$ earthquake, which produced the strongest ground motions in densely populated regions of Christchurch city during the sequence, leading to devastating damage and 185 deaths; (iii) the 13/06/2011 $M_{w} 6.0$ earthquake, which produced significant ground motions and liquefaction; and (iv) the most recent major event of 23/12/2011, which produced liquefaction in particularly susceptible areas of Christchurch city's eastern suburbs.

As a result of the close proximity of these earthquake events, severe ground motions were observed in central Christchurch and the Canterbury region, causing significant liquefaction of surficial soils and damage to commercial, industrial, and residential structures and severely impacted critical infrastructure and lifelines (NZSEE 2010, NZSEE 2011). Because the most notable ground motions were observed as a result of the 04/09/2010 and 22/02/2011 events, then this paper focuses on the characteristics of observed ground motions for these events alone. Such observations include the significance and extreme nature of the ground motions; source effects such as forward directivity; basin-generated surface waves; nonlinear response of surficial soil layers; liquefaction observation; and intense vertical ground motion amplitudes.

1 Senior Lecturer, Department of Civil \& Nat Res Engineering, University of Canterbury, Christchurch, New Zealand, Email: brendon.bradley@canterbury.ac.nz 

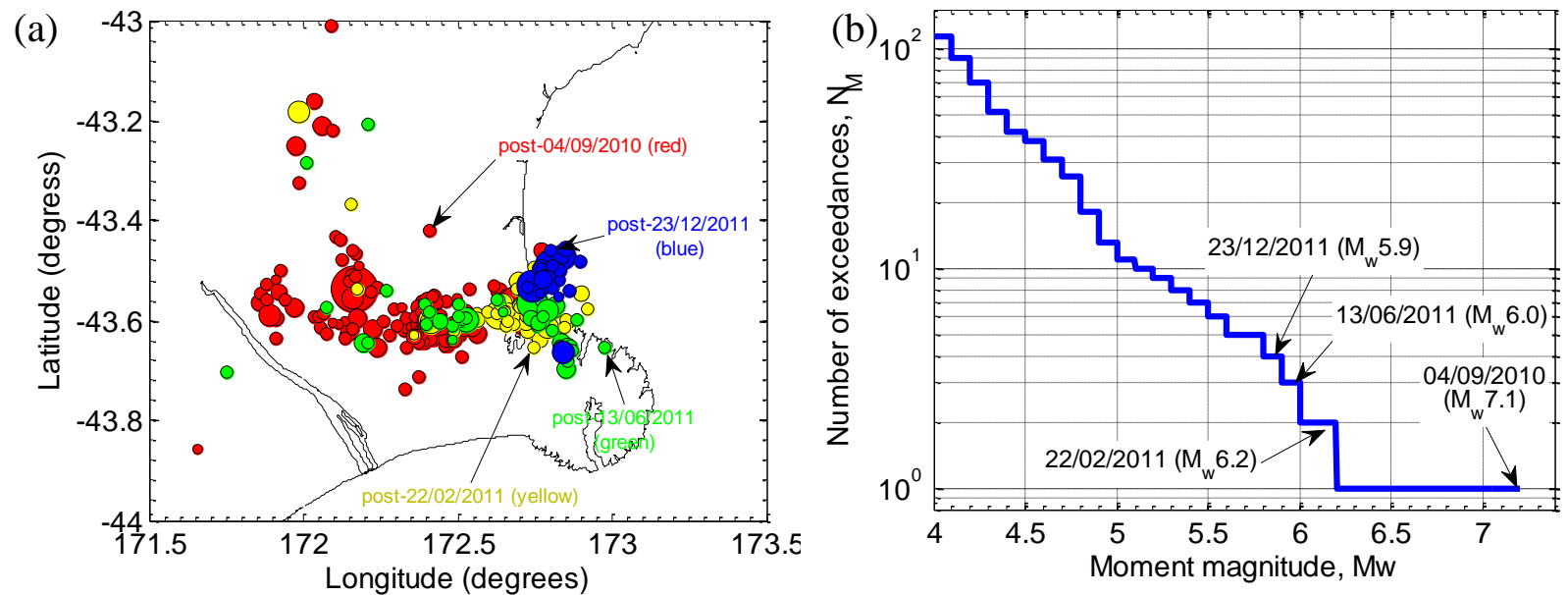

Figure 1. (a) Spatial distribution of events in the Canterbury earthquake sequence (marker size proportional to event magnitude); and (b) Distribution of event magnitudes observed from 04/09/2010$31 / 12 / 2011$.

\section{SUMMARY OF OBSERVED STRONG MOTIONS}

Numerous high quality ground motion time series were recorded in the 04/09/2010 Darfield and 22/02/2011 Christchurch earthquakes. Specific (tabulated) details of the ground motion amplitudes are not given here for brevity, and can be found elsewhere (e.g. Bradley 2012, Bradley and Cubrinovski 2011a). Figure 2 provides an illustration of the significance of the recorded ground motions relative to those previously recorded in NZ. Figure 2a illustrates the magnitude-distance distribution of recorded ground motions from active shallow crustal earthquakes up to 2009. Also illustrated in Figure 2a are the ground motions recorded in both the Darfield and Christchurch earthquakes. The significance of the recorded ground motions in these two earthquakes is even more apparent if the ground motions in Figure 2a are plotted in terms of their geometric mean horizontal peak ground acceleration $(P G A)$. Figure $2 \mathrm{~b}$ illustrates the number of ground motions exceeding specific values of $P G A$. It can be seen that up to 2009, the maximum $P G A$ recorded in New Zealand was $0.39 \mathrm{~g}$, with only 7 observed ground motions exceeding $0.2 \mathrm{~g} P G A$. Figure $2 \mathrm{~b}$ also illustrates the $P G A$ exceedance values observed in the Darfield and Christchurch earthquakes. With the addition of these two events (not to mention records obtained from numerous significant aftershocks which are not discussed herein) it can be seen that horizontal ground motions of up to $1.41 \mathrm{~g}$ have now been recorded, with 12 observed ground motions exceeding $0.4 \mathrm{~g}$ and 39 exceeding $0.2 \mathrm{~g}$.

(a)

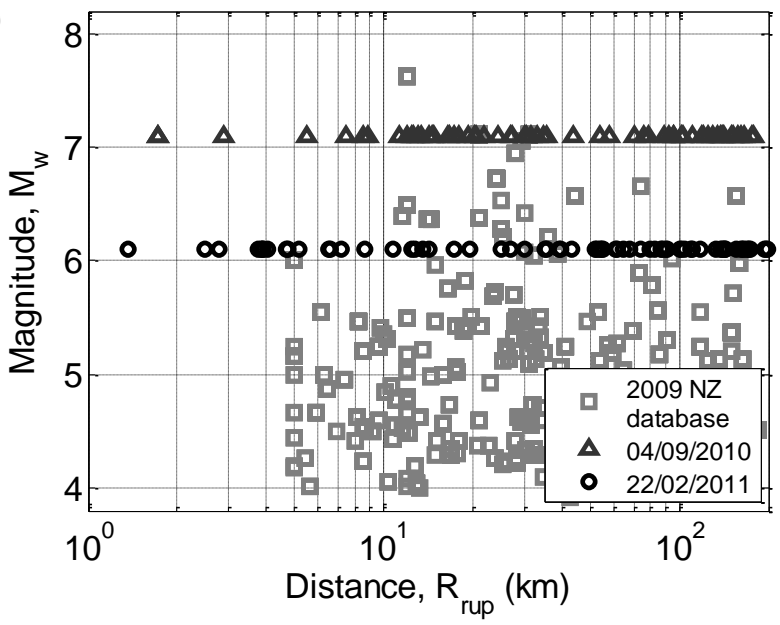

(b)

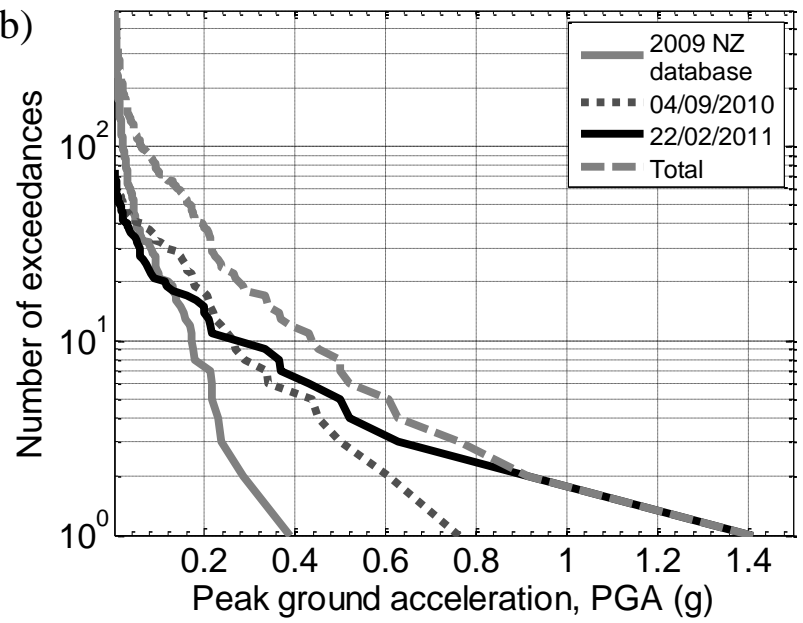

Figure 2. Significance of the 22/02/2011 Christchurch and 04/09/2010 Darfield earthquakes in relation to previously recorded ground motions in New Zealand: (a) magnitude-distance distribution; (b) exceeded values of peak ground acceleration. 


\section{EXTREME GROUND MOTIONS}

Severe ground motion amplitudes were recorded in both the horizontal and vertical components at several strong motion station locations. Figure 3 illustrates details of the ground motions observed at Pages Road (PRPC) and Heathcote Valley (HVSC) in these two events. In particular, maximum PGA's in the vertical component of $2.21 \mathrm{~g}$ and $1.88 \mathrm{~g}$ were observed at HVSC and PRPC, respectively, in the 22 February 2011 Christchurch earthquake. The ground motion at PRPC also experienced significant forward directivity effects which are evident in the long-period content of the fault normal component in Figure 3a. Figure $3 \mathrm{c}$ and Figure 3d illustrate the geometric mean horizontal and

(a)

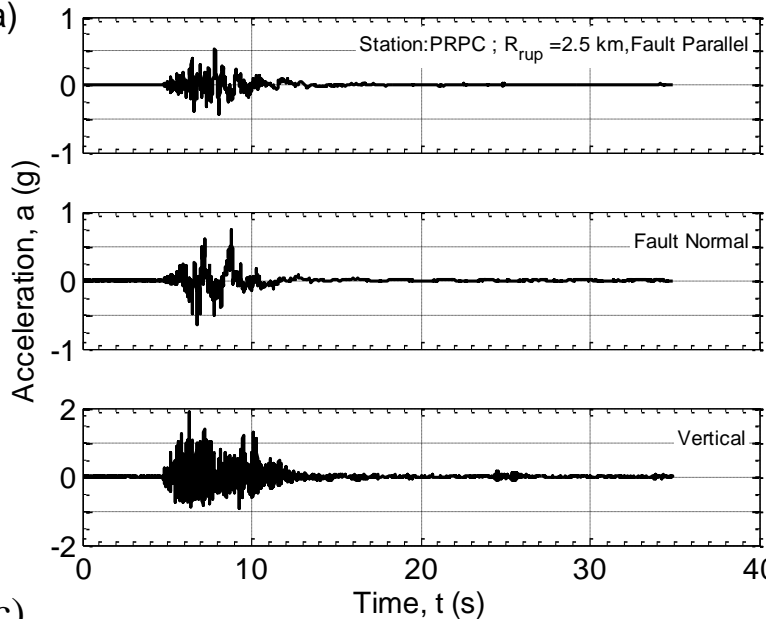

(c)

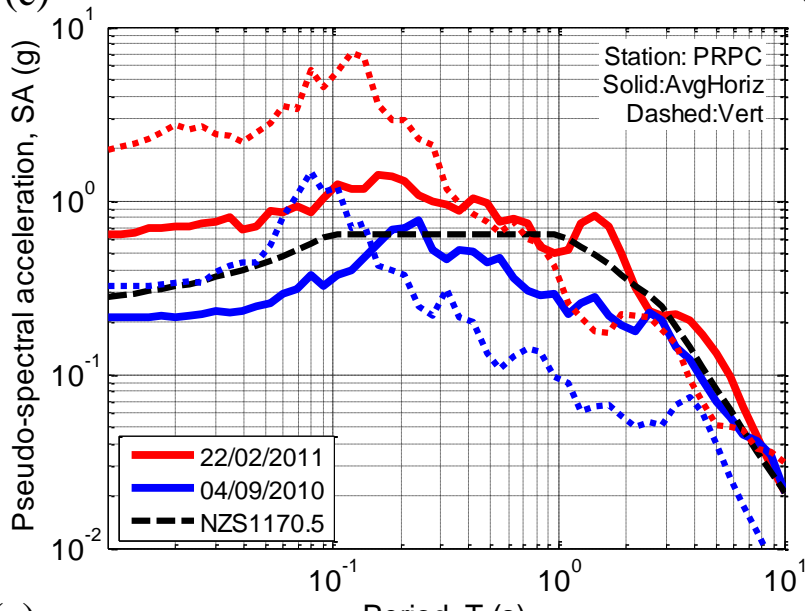

(e)

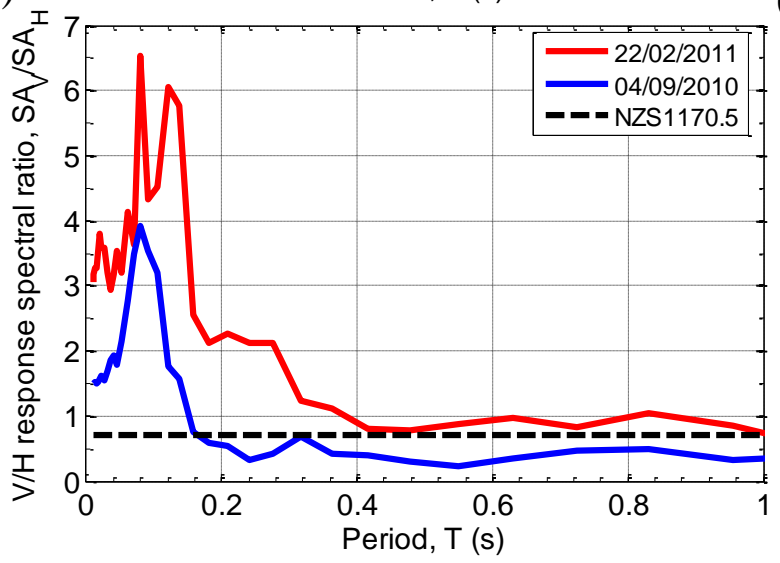

(b) 1.5

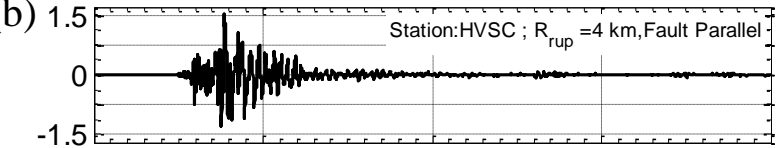

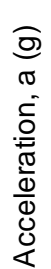
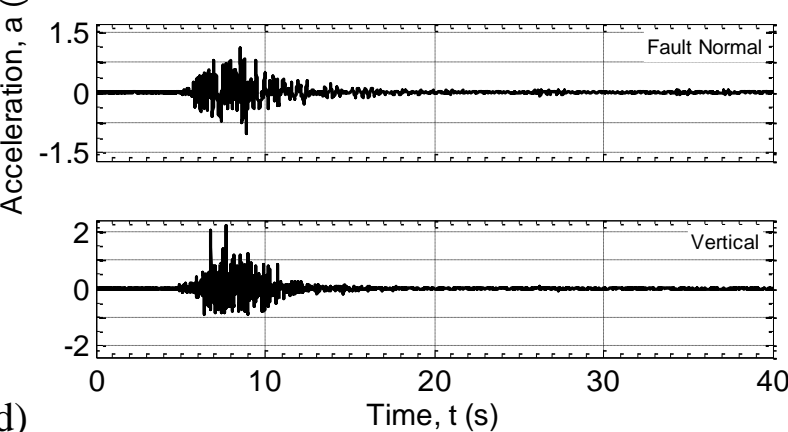

(d)



(f)

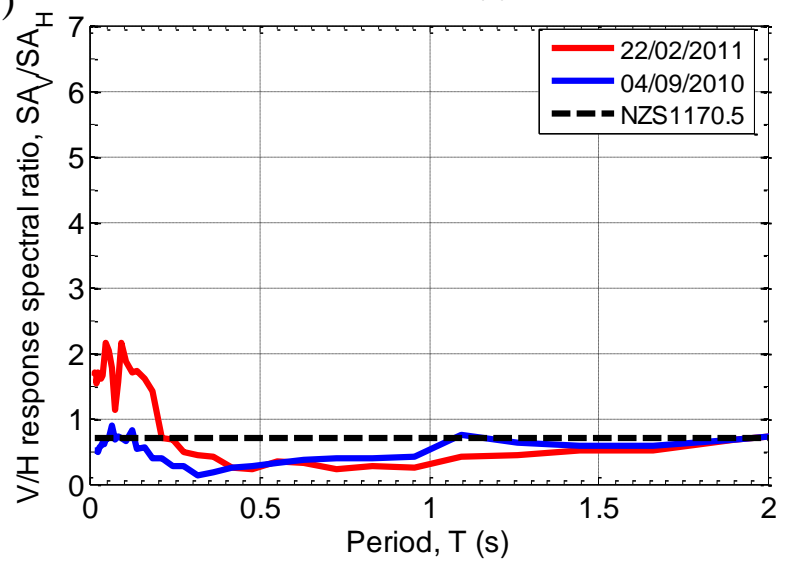

Figure 3. Extreme ground motions observed at Pages Road (PRPC) and Heathcote Valley

(HVSC) in the 22 February 2011 Christchurch earthquake in terms of acceleration time history, pseudo-acceleration response spectra, and vertical to horizontal spectral ratios. Note the different scale used for vertical acceleration time histories in Figure 3a and Figure $3 \mathbf{b}$. 
vertical pseudo-acceleration response spectra at PRPC and HVSC during both the Christchurch and Darfield earthquakes, and Figure $3 \mathrm{e}$ and Figure $3 \mathrm{f}$ illustrate the vertical-to-horizontal spectral ratios at these two sites in these two events. It can be clearly seen that the nature of the surface ground motion at each of these sites is similar in each of the two events, but fundamentally different between the two sites. For example, the response at PRPC is dominated by a relatively 'flat' response spectrum for high frequencies, indicative of nonlinear response in soil soft deposits. Furthermore, the vertical ground motion amplitude at high frequencies is particularly large (i.e. Figure 3e), indicating a soil deposit with high compressibility, that is, low P-wave velocity (e.g. clay, silt, peat). In contrast, the response at HVSC is characterised by large short period (i.e. $T<0.4 \mathrm{~s}$ ) ground motion with a rapid falloff in spectral ordinates at longer periods (the exception being the increase for the Darfield earthquake at long periods due to the forward directivity pulse (Bradley 2012)). The vertical-to-horizontal spectral ratio is also notably lower than that at PRPC and only larger than 1.0 for very high frequencies. In-depth analysis of the strong ground motion at HVSC indicates a strong basin edge effect at this site due to its location near the Port Hills, resulting in constructive interference between direct $S$-waves propagating through the underlying basin, and diffracted Rayleigh waves induced at the basin edge (Bradley 2012).

\section{FORWARD DIRECTIVITY SOURCE EFFECTS}

The dense strong motion instrumentation allows for a detailed assessment of the complexity of source rupture during the Darfield and Christchurch earthquakes (Beavan et al. 2011, Holden et al. 2011), in which fault slip in both events is inferred to have occurred on more than a single plane, in particular the Darfield earthquake.

From an engineering-perspective the near-source effect of greatest interest is forward directivity. Forward directivity is a phenomenon which occurs in the near-source region resulting from the alignment of the rupture front, direction of slip, and source-to-site direction. The manifestation of forward directivity is the arrival of a large portion of the radiated seismic energy in a single pulse at the beginning of the ground motion record oriented in the direction normal to the fault strike, and has a particularly large damage potential due to its large amplitude and short duration. Forward-directivity effects occur in the near source region in earthquakes of all magnitudes (Boatwright 2007), and their significance, from an engineering perspective, increases with increasing earthquake magnitude (due to a larger rupture duration). Forward directivity effects do not occur in all directions from a fault in the near-source region. If the direction of rupture propagation is 'away' from the site of interest then backward directivity effects occur, which will result in longer duration ground motion, but of a lower amplitude (Somerville 2003). Forward directivity effects were particularly significant for the 4 September 2010 Darfield earthquake as a result of its size $\left(M_{w} 7.1\right)$, strike-slip faulting mechanism and rupture propagation of the central and eastern section of the Greendale fault toward Christchurch (Bradley 2012, Holden et al. 2011). In contrast, forward directivity effects from the 22 February 2011 Christchurch earthquake are less significant, relative to the Darfield earthquake as a result of its size $\left(M_{w} 6.3\right)$, and also are prevalent only in a smaller area in the eastern suburbs of Christchurch as a result of the mis-alignment between the direction of slip on the fault and the inferred direction of rupture propagation on the fault (Aagaard et al. 2004, Bradley and Cubrinovski 2011a, Bradley and Cubrinovski 2011b, Holden 2011).

As previously noted, forward directivity effects from the 4 September 2010 Darfield earthquake are most evident in ground motions observed in the near-source region to the east of the causative faults. Figure 4 illustrates the observed velocity time histories at Templeton (TPLC) and Rolleston (ROLC), in which forward directivity effects are clearly evident with peak ground velocities (PGV's) of 80 and $100 \mathrm{~cm} / \mathrm{s}$ in the fault normal direction, as compared to approximately 30 and $60 \mathrm{~cm} / \mathrm{s}$ in the fault parallel direction, respectively. 

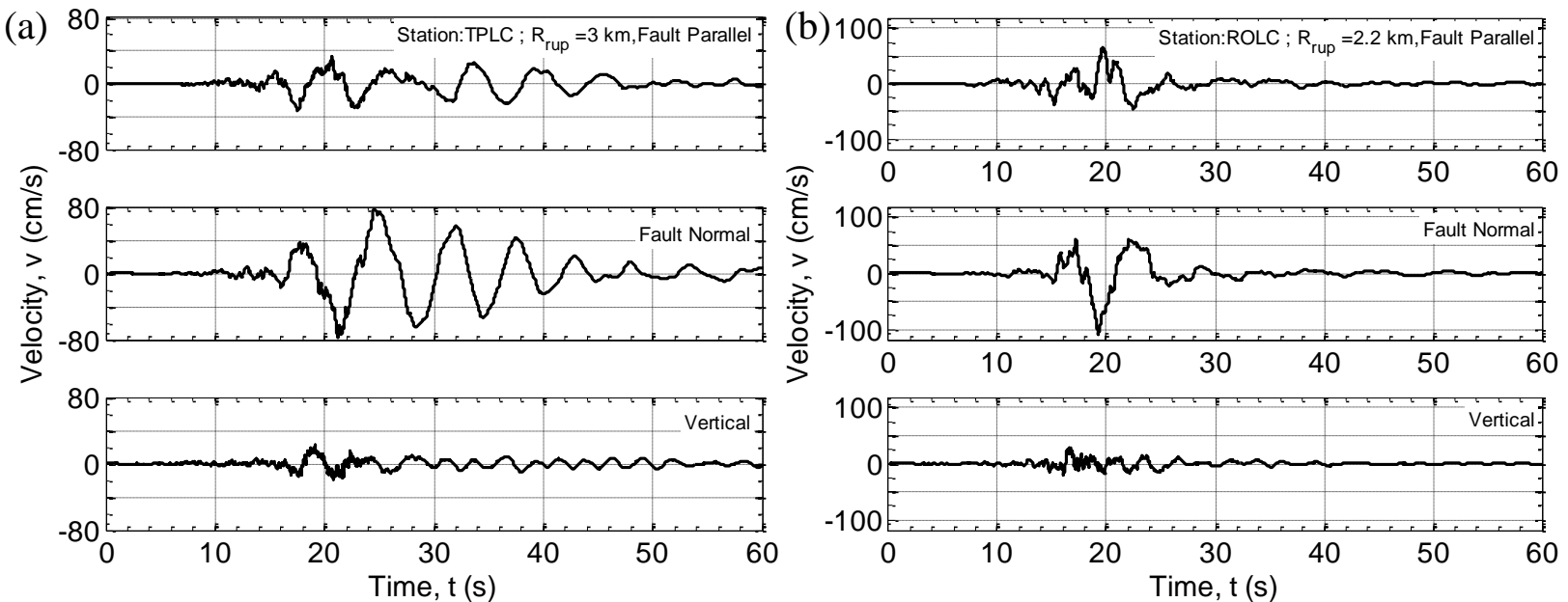

Figure 4. Evidence of strong forward directivity effects at locations to the east of the Greendale fault: (a) Templeton (TPLC); and (b) Rolleston (ROLC) resulting from the 4 September 2010 earthquake.

Figure 5 illustrates the fault normal component velocity time histories observed at the four strong motion stations located in the Christchurch central business district (CBD). It can be seen that the characteristics of the forward directivity velocity pulse are remarkably similar at all stations with PGV's ranging between $62 \mathrm{~cm} / \mathrm{s}(\mathrm{CBGS})$ and $74 \mathrm{~cm} / \mathrm{s}(\mathrm{CCCC})$. In contrast, the time history subsequent to the arrival of the velocity pulse varies significantly between the various sites illustrating the importance of both wave scattering and also shallow and deep geologic structure on site-specific site response. Figure $5 \mathrm{~b}$ illustrates the difference between the fault normal and fault parallel pseudospectral acceleration (SA) amplitudes at CHHC and CCCC. There is a ratio of SA amplitudes of the fault normal and parallel components of approximately 5 at the spectral peak of $T=2.5 \mathrm{~s}$. For comparison, Figure $5 \mathrm{~b}$ also illustrates the conventional 500-year return period response spectra prescribed for site class D soil conditions in Christchurch (NZS 1170.5 2004), as well as the maximum prescribed increase in the design spectra due to near-fault forward directivity effects. It can be seen that the maximum permissible increase in the design code response spectra (based on assuming a distance of less than $2 \mathrm{~km}$ from the fault to the site), significantly under predicts the amplification of fault normal SA amplitudes relative to those in the fault parallel orientation, despite the fact that the Christchurch CBD is approximately $15 \mathrm{~km}$ from the inferred eastern extent of the Greendale fault. Furthermore, it can be seen that the NZS1170.5 near fault factor produces an amplification over a broad period range, relative to the more narrow range over which significant amplifications are observed in Figure $5 b$.

It is noted that the near-fault amplitude specified by NZS1170.5:2004, as shown in Figure $5 \mathrm{~b}$ is based on Somerville et al. (1997) geometric mean forward-directivity amplification. This geometric mean amplification model should be used only for application to the geometric mean response spectral predictions. For NZS1170.5:2004, where the 'larger component' definition (i.e. maximum of the two recorded components) is used, the use of the Somerville et al. geometric mean forward directivity amplification is inappropriate. Somerville et al. also provide a model for the ratio of the fault normal to geometric mean components, and it is the product of these two models which should be used for consistency with NZS1170.5:2004. While changes to the near-fault factor in NZS1170.5:2004 are certainly warranted, it is noted that the Somerville et al. 'broadband' model is now outdated by several newer 'narrow-band' models (e.g. Shahi and Baker 2011).

\section{BASIN GENERATED SURFACE WAVES}

Christchurch is located on a sedimentary fan deposit with the volcanic rock of Banks peninsula located to the south east. Significant long period ground motion was observed at numerous sites in the 4 September 2010 and 22 February 2011 earthquakes resulting from surface wave generation, in 
addition to the large amplitude long period ground motion resulting from forward directivity
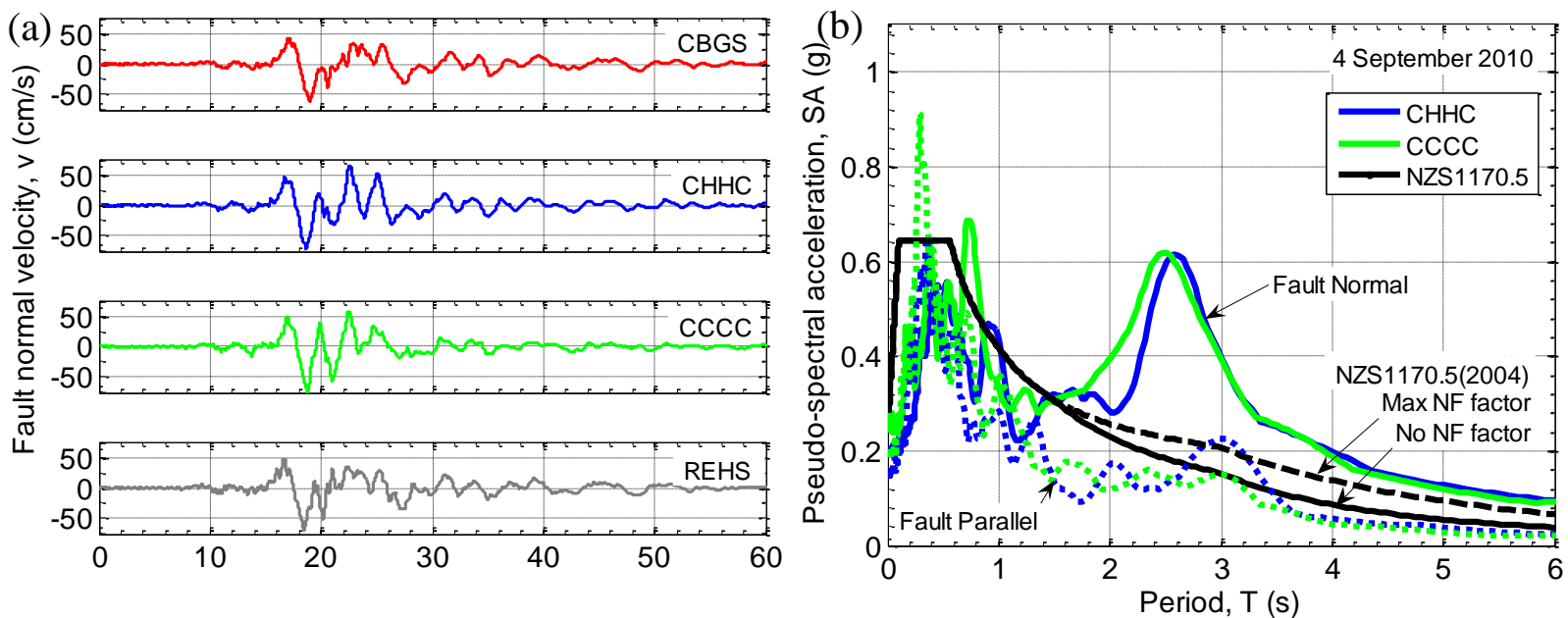

Figure 5. Forward directivity effects observed in the Christchurch central business district (CBD) resulting from the 4 September 2010 earthquake: (a) fault normal velocity time series; and (b) fault normal (plain) and fault parallel (dashed) response spectra in comparison with those prescribed by NZS1170.5:2004.

associated with source rupture effects. Figure $4 \mathrm{a}$, for example, illustrates that the velocity pulse associated with forward directivity at TPLC was subsequently followed by several cycles of basingenerated surface waves, which are strongest in the fault normal component, consistent with the strongest SH waves in this component, but also evident in the fault parallel and vertical component velocity time histories. Basin-generated surface waves were also significant in the 22 February 2011 Christchurch earthquake (Bradley and Cubrinovski 2011a), but are not elaborated upon here.

\section{NONLINEAR RESPONSE OF NEAR-SURFACE SOIL DEPOSITS}

A self-evident illustration of the significance of nonlinear soil response is possible from a comparison of two ground motions recorded at Lyttelton Port during the 22 February 2011 earthquake (Bradley and Cubrinovski 2011b). One of the obtained motions is located on engineering bedrock (LPCC), while the other is located on a relatively thin $(\sim 30 \mathrm{~m})$ colluvium layer (LPOC). Figure 6 illustrates the geometric mean pseudo-acceleration response spectra of the horizontal ground motion at the two sites. It can be seen that the observed horizontal ground motion at the LPOC site has significantly lower short period ground motion amplitude, but notably larger response spectral amplitudes at longer periods. In contrast, such site effects are not as pronounced for the vertical component with similar amplitudes and frequency content, as discussed elsewhere (Bradley and Cubrinovski 2011b).

\section{SEVERE LIQUEFACTION OBSERVATIONS IN STRONG MOTION RECORDS}

The principal cause of damage to residential property in the Canterbury earthquakes has resulted from the extreme severity and spatial extent of liquefaction (Cubrinovski et al. 2011, Cubrinovski et al. 2010). Liquefaction can be clearly observed in strong motion time series from these events (Bradley 2012, Bradley and Cubrinovski 2011b). Figure 7 illustrates the acceleration time history at Hulverstone Drive (HPSC), which is located approximately $200 \mathrm{~m}$ from the Avon River, in a region that experienced significant liquefaction. Clear evidence of cyclic mobility, in which large shear strain amplitudes in the soil deposit during strong shaking result in a drastic increase in soil shear stiffness and consequently propagation of high frequency ground motion, can be seen in the horizontal components of ground motion from $t=21 \mathrm{~s}$ onwards, and several 'spikes' manifested as a result of this phenomena are annotated in Figure 7. 


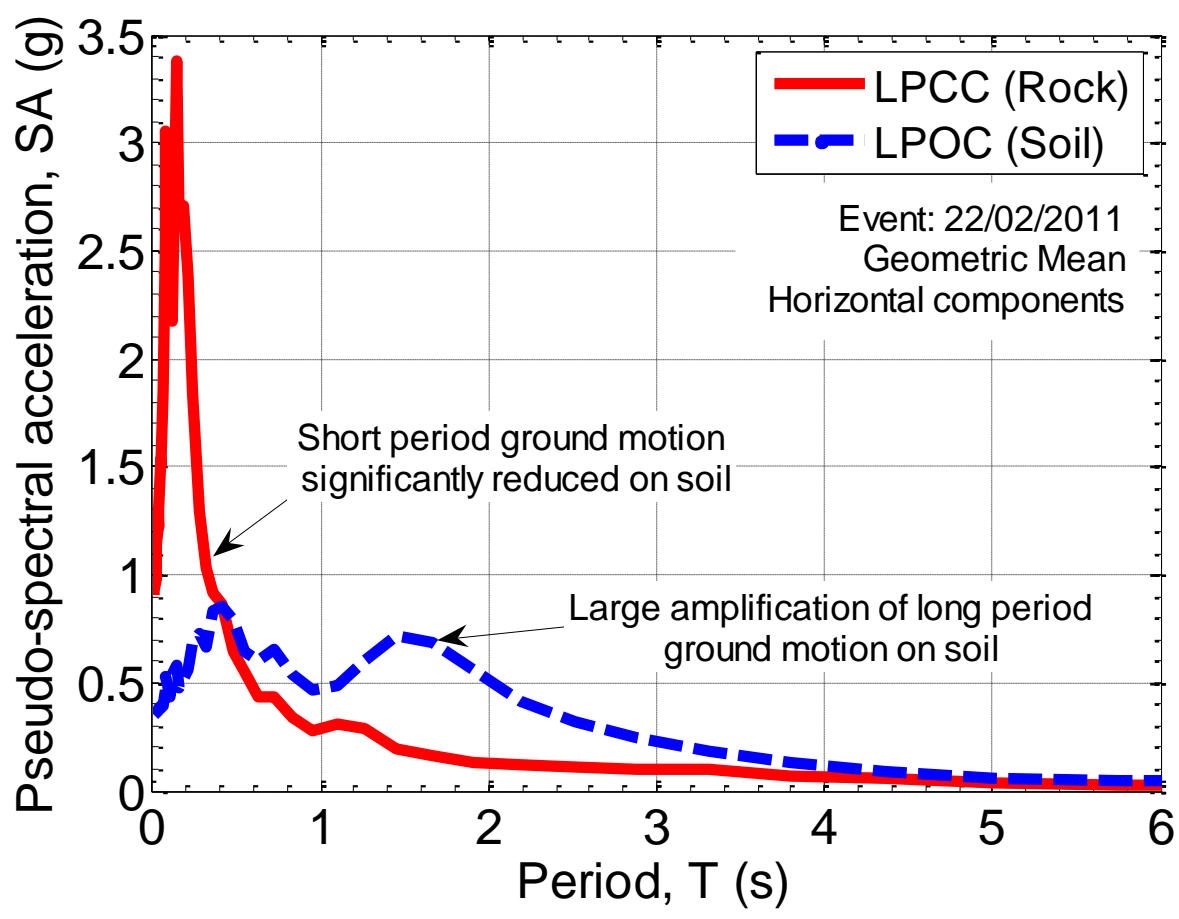

Figure 6. Comparison of the (geometric mean) horizontal ground motion response spectra at Lyttelton Port during the 22 February 2011 earthquake illustrating the importance of surficial soil response.

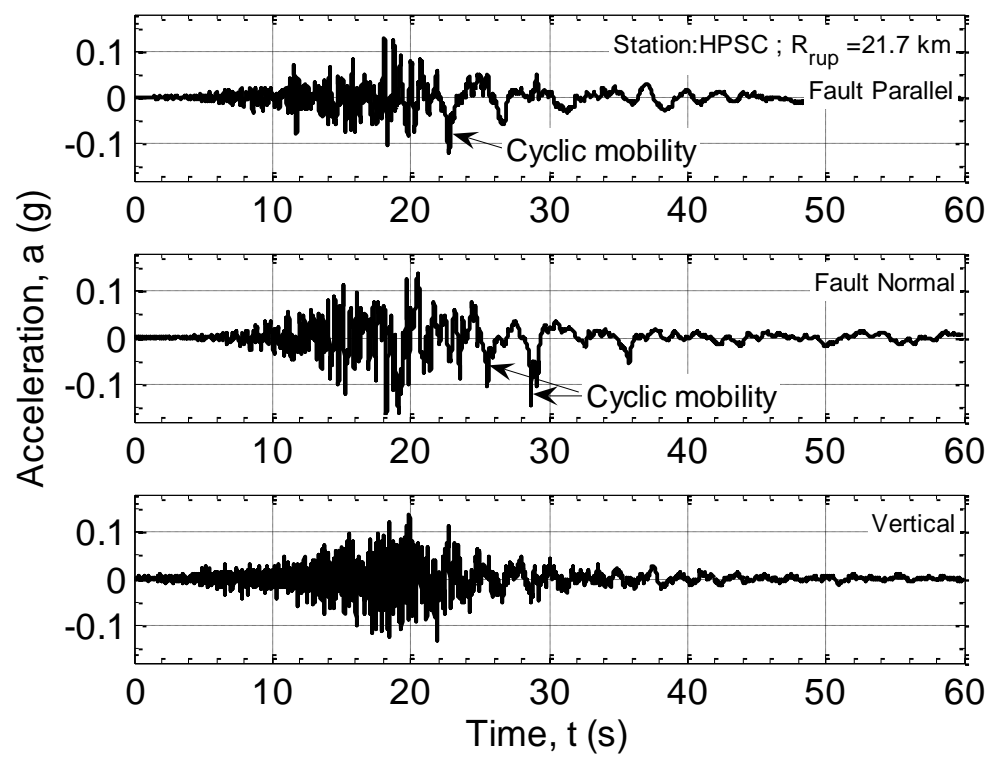

Figure 7. Evidence of liquefaction in the form of cyclic mobility in the acceleration time history recorded at Hulverstone Drive (HPSC) during the 22/02/2011 Christchurch earthquake.

\section{STRONG VERTICAL GROUND MOTIONS}

Large ground motion amplitudes were observed in the vertical component at various locations in both the 4 September 2010 and 22 February 2011 earthquakes (particularly the latter). Such large vertical accelerations can be understood physically, because the majority of strong motion stations are located on soil sites, and for soil sites in sedimentary basins large vertical accelerations at near-source locations can result from the conversion of inclined SV-waves to P-waves at the sedimentary basin interface which are subsequently amplified and refracted towards vertical incidence due to the basin P- 
wave gradient (Silva 1997). That is, large vertical accelerations observed at near-source locations are expected, and are not an indication on their own of any peculiarities associated with the earthquake source.

Figure 8a illustrates the geometric mean horizontal pseudo-acceleration response spectra at Pages Road (PRPC), Christchurch Hospital (CHHC), and Riccarton High School (RHSC), and Figure 8b the corresponding vertical-to-horizontal ratios. As has been commonly observed in numerous other studies, it can be seen that the vertical-to-horizontal (V-to-H) spectral ratio is largest at high frequencies with values that can be significantly greater than 1.0 , and tends to reduce rapidly for vibration periods greater than $T=0.1 \mathrm{~s}$; and also as a function of source to site distance (i.e. $R_{\text {rup }}=2.5 \mathrm{~km}, 3.8 \mathrm{~km}$, and $6.5 \mathrm{~km}$ for PRPC, CHHC, and RHSC, respectively (Bradley and Cubrinovski 2011b)). Figure 8c and Figure 8d illustrate the V-to-H spectral ratios for vibration periods, $T=0.0$ and $0.2 \mathrm{~s}$ as a function of source-to-site distance for both the 22 February 2011 Christchurch and 4 September 2010 Darfield earthquakes. Also shown for comparison is the empirical model of Bozorgnia and Campbell (2004), and the prescribed ratio of 0.7 for the development of vertical design spectra in NZS1170.5 (2004). Firstly, it can be clearly seen that V-to-H ratios above 1.0 are frequently observed for distances up to $R_{r u p}=40 \mathrm{~km}$ in both these events (as well as other historical earthquakes worldwide (Bozorgnia and Campbell 2004)), and hence the code prescription of 0.7 is significantly un-conservative. Secondly, it can be seen that while there is significant scatter in the observed ratios, the Bozorgnia and Campbell empirical model is able to capture the overall trends in the observations, except for $R_{r u p}<10 \mathrm{~km}$ for which it underestimates the observed ratios. Comparison
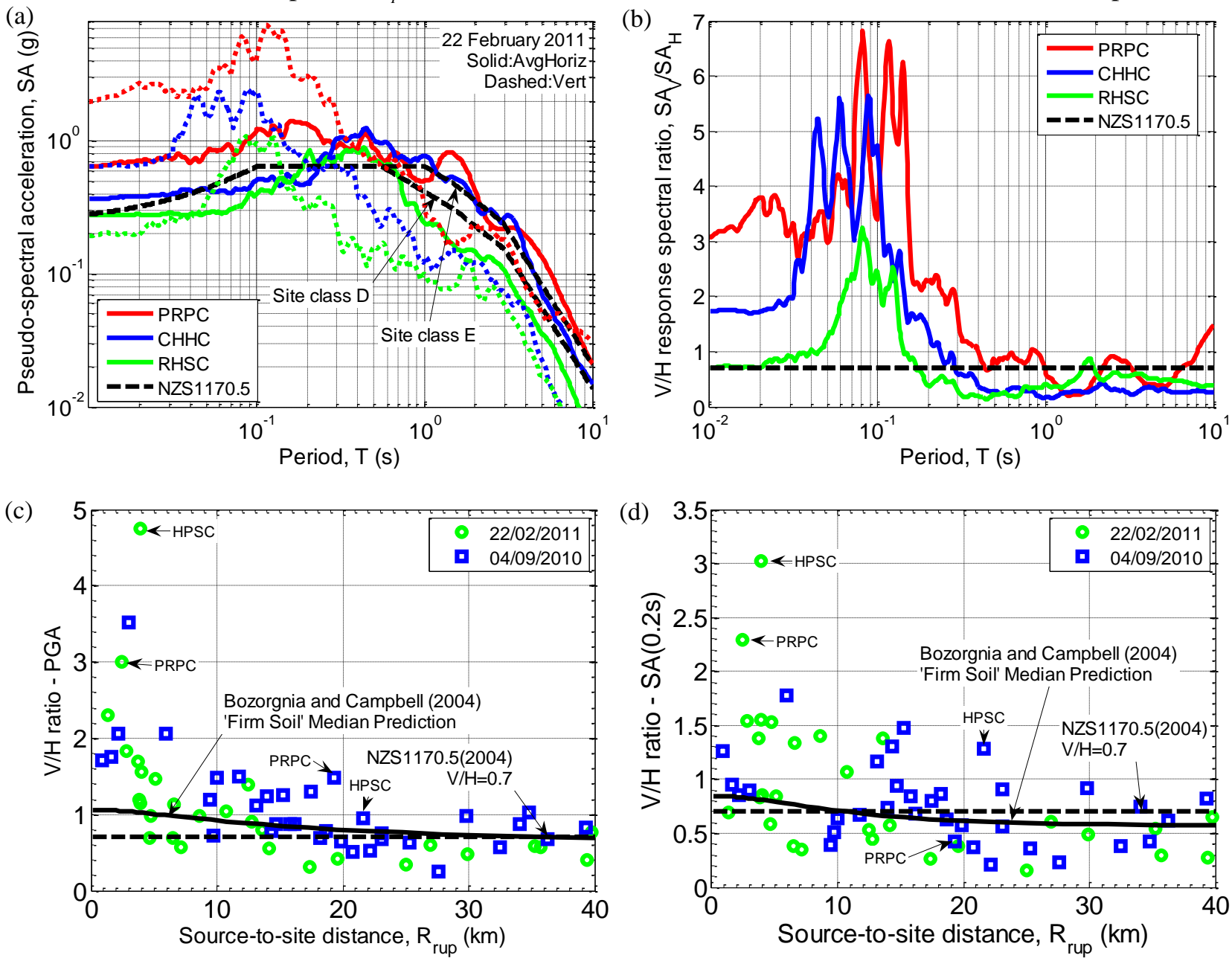

Figure 8. Vertical ground motion response spectral amplitudes observed: (a)-(b) Example geometric mean horizontal and vertical response spectra and their vertical-to-horizontal ratio;

(c)-(d) vertical-to-horizontal response spectral ratios for $\mathbf{T}=0.0$ and $0.2 \mathrm{~s}$ as a function of

distance observed in the 4 September 2010 Darfield and 22 February 2011 Christchurch earthquakes and comparison with the empirical prediction of Bozorgnia and Campbell (2004). 
of the observations from the Darfield and Christchurch earthquakes also illustrates that the ratios, on average, are principally a function of source-to-site distance and there is no evidence for a systematic differences between the two events due to their different magnitude and style of faulting. This lack of average dependence the seismic source features is consistent with that of Bozorgnia and Campbell (2004). Comparison of the ratios observed at the same station in the two different events (annotated in the figures for PRPC and HPSC) illustrates that there is some systematic site effect, for example, HPSC is always above the average prediction, but this is not always the case for PRPC with the ratio for $T=0.2 \mathrm{~s}$ well above the prediction in the Christchurch earthquake, but below the prediction in the Darfield earthquake. Given that vertical ground motion is only significant at very high frequencies, then it is expected to be strongly correlated with near-surface P-wave velocity structure, and some of the fluctuations observed in Figure 8 are likely the result of variability in the amplitude of the horizontal ground motion on the $\mathrm{V}$-to-H ratio (due to nonlinearities for example).

\section{CONCLUSIONS}

The Canterbury earthquake sequence has produced severe ground motions in densely populated regions of Christchurch city from 04/09/2010-31/12/2011. As a result of a dense instrumentation network near the causative faults, numerous strong ground motions have been recorded. For the 4 September 2010 Darfield and 22 February 2011 Christchurch earthquakes, in particular, the dense array of ground motions records enable significant insight into features of the earthquake source, forward directivity during rupture, basin-generated surface waves, and local site effects; some of which were briefly discussed in this paper.

\section{ACKNOWLEDGEMENTS}

Financial support from the New Zealand Earthquake Commission (EQC) and Natural Hazards Research Platform (NHRP) is gratefully appreciated.

\section{REFERENCES}

Aagaard, B. T., J. F. Hall, T. H. Heaton, (2004). Effects of Fault Dip and Slip Rake Angles on Near-Source Ground Motions: Why Rupture Directivity Was Minimal in the 1999 Chi-Chi, Taiwan, Earthquake, Bulletin of the Seismological Society of America, 94, 155-170. 10.1785/0120030053

Beavan, J., E. Fielding, M. Motagh, S. Samsonov, N. Donnelly, (2011). Fault Location and Slip Distribution of the 22 February $2011 \mathrm{Mw} 6.2$ Christchurch, New Zealand, Earthquake from Geodetic Data, Seismological Research Letters, 82, 789-799. 10.1785/gssrl.82.6.789

Boatwright, J., (2007). The Persistence of Directivity in Small Earthquakes, Bulletin of the Seismological Society of America, 97, 1850-1861. 10.1785/0120050228

Bozorgnia, Y., K. W. Campbell, (2004). The vertical-to-horizontal response spectral ratio and tentative procedures for developing simplified V/H and vertical design spectra, Journal of Earthquake Engineering, 8, 175-207.

Bradley, B. A., (2012). Strong ground motion characteristics observed in the 4 September 2010 Darfield, New Zealand earthquake, Soil Dynamics and Earthquake Engineering, 42, 32-46. 10.1016/j.soildyn.2012.06.004

Bradley, B. A., M. Cubrinovski, (2011a). Near-source strong ground motions observed in the 22 February 2011 Christchurch earthquake, Bulletin of the New Zealand Society for Earthquake Engineering, 44, 181-194.

Bradley, B. A., M. Cubrinovski, (2011b). Near-source Strong Ground Motions Observed in the 22 February 2011 Christchurch Earthquake, Seismological Research Letters, 82, 853-865. 10.1785/gssrl.82.6.853

Cubrinovski, M., B. A. Bradley, L. Wotherspoon, A. G. Green, J. Bray, C. Wood, M. Pender, C. R. Allen, A. Bradshaw, G. Rix, M. Taylor, K. Robinson, D. Henderson, S. Giorgini, K. Ma, A. Winkley, J. Zupan, T. D. O'Rourke, G. DePascale, D. L. Wells, (2011). Geotechnical Aspects of the 22 February 2011 Christchurch Earthquake, Bulletin of the New Zealand Society for Earthquake Engineering, 44, 205-226.

Cubrinovski, M., R. A. Green, J. Allen, S. A. Ashford, E. Bowman, B. A. Bradley, B. Cox, T. C. Hutchinson, E. Kavazanjian, R. P. Orense, M. Pender, M. Quigley, L. Wotherspoon, (2010). Geotechnical reconnaissance of 
the 2010 Darfield (Canterbury) earthquake, Bulletin of the New Zealand Society for Earthquake Engineering, 43, 243-320.

Holden, C., (2011). Kinematic Source Model of the 22 February $2011 \mathrm{Mw} 6.2$ Christchurch Earthquake Using Strong Motion Data, Seismological Research Letters, 82, 783-788. 10.1785/gssrl.82.6.783

Holden, C., J. Beavan, B. Fry, M. Reyners, J. Ristau, R. Van Dissen, P. Villamor, M. Quigley, (2011). Preliminary source model of the Mw7.1 Darfield earthquake from geological, geodetic, and seismic data, in 9th Pacific Conference on Earthquake Engineering: Auckland, New Zealand. 8.

NZS 1170.5, (2004). Structural design actions, Part 5: Earthquake actions - New Zealand. Standards New Zealand: Wellington, New Zealand. 82.

NZSEE, (2010). Special Issue: Preliminary observations of the 2010 Darfield (Canterbury) Earthquakes, Bulletin of the New Zealand Society for Earthquake Engineering, 43, 215-439.

NZSEE, (2011). Special Issue: Preliminary observations of the 2011 Christchurch Earthquake, Bulletin of the New Zealand Society for Earthquake Engineering, 44, 181-430.

Shahi, S. K., J. W. Baker, (2011). An Empirically Calibrated Framework for Including the Effects of Near-Fault Directivity in Probabilistic Seismic Hazard Analysis, Bulletin of the Seismological Society of America, 101, 742-755. 10.1785/0120100090

Silva, W. J., (1997). Characteristics of vertical strong ground motions for applications to engineering design, FHWA/NCEER Workshop on the National Representation of Seismic Ground Motion for New and Existing Highway Facilities, Burlingame, CA, Proceedings, National Center for Earthquake Engineering Research, Technical Report NCEER-97-0010, Buffalo, New York.

Somerville, P. G., (2003). Magnitude scaling of the near fault rupture directivity pulse, Physics of The Earth and Planetary Interiors, 137, 201-212. Doi: 10.1016/s0031-9201(03)00015-3

Somerville, P. G., N. F. Smith, R. W. Graves, N. A. Abrahamson, (1997). Modification of empirical strong ground motion attenuation relations to include the amplitude and duration effects of rupture directivity, Seismological Research Letters, 68, 199-222. 